\title{
Faktor Risiko yang Mempengaruhi Terjadinya Stroke Non Hemoragik pada Pasien di RS RK Charitas dan RS Myria Palembang
}

\author{
Bangun Dwi Hardika ${ }^{1}$, M.Yuwono ${ }^{2}$, HM. Zulkarnain ${ }^{3}$ \\ ${ }^{1}$ Program Studi Magister Ilmu Kesehatan Masyarakat, Universitas Sriwijaya \\ ${ }^{2,3}$ Dosen Program Studi Magister Ilmu Kesehatan Masyarakat Universitas Sriwijaya \\ Email : bangunhardika@gmail.com
}

Submitted : 19/06/2020

Accepted: $1 / 07 / 2020$

Published: 07/09/2020

\begin{abstract}
Non-hemorrhagic stroke is a frequent case of stroke caused by blockage of blood vessels and the accumulation of changeable and unchangeable risk factors. The impact of stroke is a long-term physical and functional disorder that affects the life quality of the patient and the family. The aim of this study was to analyze the factors that influence the occurrence of non-hemorrhagic stroke. This study is an observational analytic epidemiological study with case control research design conducted in 2 private hospitals. The samples were selected sequentially with a ratio of 1: 2 (case: control) consisting of 50 patients with non-hemorrhagic stroke and 100 patients without nonhemorrhagic stroke. The data was analyzed by univariate, bivariate, and multivariate analysis method by using binary logistic regression. The results of risk factor analysis which were independently associated were Total Blood Cholesterol, History of Hypertension, Systolic Blood Pressure, Diastolic Blood Pressure, and Cardiac Examination. The multivariate analysis showed that the risk factors affecting non hemorrhagic stroke were History of Hypertension (OR: 6,476, $p$ $=0.000,95 \%$ CI: 2,338-17,935), Total Blood Cholesterol Level $\geq 200 \mathrm{mg} / \mathrm{dl}(\mathrm{OR}: 6,139, p=0.000$, 95\% CI: 2,334-16,148), Education Level (OR: 0,311, $p=0.009,95 \%$ CI: 0,129-0,747), Gender (OR: 0.379, $p=0.022,95 \%$ CI: 0.165-0.871), and Obesity (OR: 2,217, $p=0.080,95 \%$ CI: 0.9105.401). As a conclusion, there were 5 variables of risk factors that influence to Non Hemorrhagic Stroke. If those variables of risk factors were exist in the respondent, the risk of a non hemorrhagic Stroke reached $81.6 \%$. It was suggested that the patients made an effort on preventions by maintaining a healthy lifestyle and controlling risk factors affecting the occurrence of nonhemorrhagic stroke.
\end{abstract}

Keywords: hemorrhagic, non-hemorrhagic, stroke

\begin{abstract}
Abstrak
Stroke non hemoragik merupakan kasus stroke yang sering terjadi diakibatkan oleh tersumbatnya pembuluh darah serta akumulasi dari faktor risiko yang dapat dirubah dan tidak dapat dirubah. Dampak stroke adalah gangguan fisik dan fungsional tubuh yang bersifat jangka panjang yang mempengaruhi perubahan kualitas hidup penderita dan keluarga. Tujuan penelitian untuk menganalisis faktor-faktor risiko yang mempengaruhi terjadinya Stroke non hemoragik. Merupakan penelitian epidemiologik analitik observasional dengan desain kasus kontrol yang dilakukan di 2 Rumah Sakit swasta. Sampel diambil secara consecutive dengan perbandingan $1: 2$ (kasus : kontrol) terdiri dari 50 pasien Stroke non hemoragik dan 100 pasien bukan Stroke non hemoragik. Analisis dilakukan secara univariat, bivariat dan multivariat menggunakan Regresi Binary Logistic. Hasil penelitian faktor risiko yang secara mandiri berhubungan adalah Kadar Kolesterol Darah Total, Riwayat Hipertensi, Tekanan Darah Sistolik, Tekanan Darah Diastolik, dan Pemeriksaan Jantung. Hasil analisis Multivariat menunjukkan bahwa faktor risiko yang berpengaruh terhadap Stroke Non Hemoragik adalah Riwayat Hipertensi (OR: 6,476, p=0.000, 95\%CI: 2,338-17,935), Kadar Kolesterol Darah Total $\geq 200 \mathrm{mg} / \mathrm{dl}$ (OR:6,139, $\mathrm{p}=0.000$, 95\%CI:2.334-16.148), Tingkat Pendidikan (OR: 0,311, p=0.009, 95\% CI: 0,129-0,747), Jenis Kelamin (OR: 0.379, p=0.022, 95\%CI: 0.165-0.871) dan Obesitas (OR: 2,217, p=0.080, 95\%CI: 0.910-5,401). Simpulan terdapat 5 variabel faktor risiko yang berpengaruh terhadap Stroke Non
\end{abstract}


Hemoragik. Jika ke 5 variabel faktor risiko ini ada pada responden maka risiko seorang mengalami Stroke non hemoragik adalah $81.6 \%$. Saran penting melakukan pencegahan dengan menjaga pola hidup sehat dan mengendalikan faktor risiko yang mempengaruhi terjadinya Stroke non hemoragik.

Kata Kunci : hemoragik, non hemoragik, stroke

\section{PENDAHULUAN}

Stroke adalah gangguan neurologik mendadak yang berlangsung cepat (dalam beberapa jam), yang diakibatkan oleh berhentinya suplai darah ke bagian otak. Berdasarkan data dari seluruh dunia, stroke adalah penyebab kematian tersering dengan kemungkinan meninggal 30\% sampai 35\%, dan penyebab utama kecacatan. Angka kematian setiap tahun akibat stroke baru adalah lebih dari 200.000 dan insiden stroke secara nasional diperkirakan adalah 750.000 per tahun, dengan 200.000 diantaranya adalah penderita stroke baru (Windira 2016).

Prevalensi stroke di Indonesia berdasarkan diagnosis tenaga kesehatan diperkirakan sebanyak 1.236 .825 orang atau sebesar 7,0 per 1.000 penduduk. Sedangkan berdasarkan diagnosis tenaga kesehatan dari gejala stroke diperkirakan sebanyak 2.137.941 orang atau sebesar 12,1 per 1.000 penduduk (Yuniardi, 2010).

Stroke diklasifikasikan menjadi dua yaitu stroke non hemoragik dan stroke hemoragik. Stroke non hemoragik merupakan kasus stroke yang sering terjadi dengan presentase $85 \%^{3}$, yang disebabkan oleh tersumbatnya pembuluh darah akibat penyakit tertentu seperti aterosklerosis, arteritis, trombus dan embolus. Faktor risiko terjadinya stroke non hemoragik, antara lain hipertensi, diabetes mellitus (DM), hiperkolesterol, merokok, komsumsi alkohol, Atrial fibrillation dan faktor risiko lainnya seperti Obesitas, aktifitas fisik, penggunaan obat terlarang dan penggunaan kontrasepsi oral ( Depkes RI, 2013).

Pasien paska stroke mengalami gangguan fisik dan fungsional tubuh yang bersifat jangka panjang dan menimbulkan gangguan respon psikologis yang mempengaruhi perubahan kualitas hidupnya. Selain dampak terhadap penderita, stroke juga menjadi masalah yang sangat berat bagi keluarga, karena sebagian besar pasien stroke akan mengalami hemiplegia atau kelumpuhan sebelah bagian tubuh ( Kariasa, 2009).

Rata-rata biaya tinggal di Rumah Sakit untuk pasien stroke di usia muda adalah 34.886 dolar US untuk stroke iskemik, 146.307 dolar US untuk perdarahan subarachnoid, dan 94.482 dolar US untuk pendarahan intraserebral ( Ellis, 2010).

Rekomendasi dari Organisasi Stroke Eropa adalah pencegahan stroke primer dan sekunder. Pencegahan stroke primer dengan mengurangi risiko stroke pada subjek tanpa gejala atau pada faktor risiko stroke yang dapat diubah, sedangkan pencegahan stroke sekunder bertujuan untuk mengurangi risiko stroke lain ${ }^{7}$. Tujuan analisis ini untuk mengetahui faktor-faktor risiko yang berpengaruh terhadap terjadinya stroke non hemoragik, meliputi faktor risiko yang dapat diubah dan yang tidak dapat diubah di RS RK Charitas dan RS Myria Palembang.

\section{METODE PENELITIAN}

Penelitian ini merupakan penelitian epidemiologik analitik observasional Pengumpulan data dilakukan secara retrospektif dengan menggunakan rancangan penelitian kasus kontrol. Sampel diambil secara consecutive dengan perbandingan $1: 2$ (kasus : kontrol) terdiri dari 50 pasien Stroke non hemoragik dan 100 pasien bukan Stroke non hemoragik. Sampel dalam penelitian ini adalah (1)Kasus adalah pasien stroke non hemoragik yang dirawat inap di Rumah Sakit RK Charitas dan Rumah Sakit Myria Palembang, (2)Kontrol adalah pasien bukan 
penderita stroke non hemoragik yang dirawat inap di Rumah Sakit RK Charitas dan Rumah Sakit Myria Palembang.

\section{HASIL DAN PEMBAHASAN}

\section{Analisis Univariat}

Berdasarkan karakteristik responden pada penelitian ini diketahui sebanyak $56,7 \%$ adalah responden dengan kategori umur $\geq 55$ tahun, sebanyak 55,3\% responden berjenis kelamin laki-laki, sebanyak $50,7 \%$ responden dengan tingkat pendidikan tinggi, sebanyak $57,3 \%$ responden tidak bekerja.

Sementara berdasarkan karakteristik faktor risiko yang dapat dirubah diketahui sebanyak $32,7 \%$ adalah responden dengan kebiasaan merokok, sebanyak $96,7 \%$ responden ridak rutin melakukan aktifitas fisik, sebanyak $24 \%$ responden pada kategori obesitas, sebanyak 25,3\% responden dengan kadar gula darah sewaktu $\geq 200 \mathrm{mg} / \mathrm{dl}$, sebanyak $24 \%$ responden dengan kadar gula darah puasa $\geq 126 \mathrm{mg} / \mathrm{dl}$, sebanyak $24 \%$ responden dengan kadar kolesterol total $\geq 200 \mathrm{mg} / \mathrm{dl}$, sebanyak $22,7 \%$ responden dengan kadar trigliserida tidak normal, sebanyak $66 \%$ responden memiliki riwayat hipertensi, sebanyak $54,7 \%$ responden dengan tekanan darah sistolik $\geq 140 \mathrm{~mm} / \mathrm{Hg}$, sebanyak 32,7\% responden dengan tekanan darah diastolik $\geq 90 \quad \mathrm{mg} / \mathrm{Hg}, \quad$ dan $\quad 51,3 \%$ responden dengan kelainan jantung.

\section{Analisis Bivariat}

Berdasarkan hasil uji statistik pada alpha 5\% didapatkan 5 variabel yang memiliki hubungan bermakna dengan stroke non hemoragik yaitu variabel kadar kolesterol darah total dengan $\mathrm{p}=0,002$, Riwayat hipertensi dengan $\mathrm{p}=0,001$, tekanan darah sistolik dengan $\mathrm{p}=0,001$, tekanan darah diastolik dengan $\mathrm{p}=0,008$, kelainan jantung dengan $\mathrm{p}=0,007$ (tabel 1)

Tabel 1 Hubungan Faktor Risiko Dengan Terjadinya Stroke Non Hemoragik

\begin{tabular}{|c|c|c|c|c|c|c|}
\hline \multirow[t]{2}{*}{ Variabel Penelitian } & \multicolumn{2}{|c|}{ Kasus } & \multicolumn{2}{|c|}{ Kontrol } & \multirow[t]{2}{*}{ p-value } & \multirow{2}{*}{$\begin{array}{c}\text { OR } \\
(95 \% \mathrm{CI})\end{array}$} \\
\hline & $\mathrm{n}$ & $(\%)$ & $\mathrm{n}$ & $(\%)$ & & \\
\hline \multicolumn{7}{|l|}{ Usia } \\
\hline$-\geq 55$ Tahun & 32 & 64,0 & 53 & 53,0 & \multirow{2}{*}{0,268} & 1,577 \\
\hline$-<55$ Tahun & 18 & 36,0 & 47 & 47,0 & & $(0,784-3,169)$ \\
\hline \multicolumn{7}{|l|}{ Jenis Kelamin } \\
\hline - Laki-laki & 33 & 66,0 & 50 & 50,0 & \multirow[t]{2}{*}{0,092} & 1,941 \\
\hline - Perempuan & 17 & 34,0 & 50 & 50,0 & & $(0,960-3,926)$ \\
\hline \multicolumn{7}{|l|}{ Pendidikan } \\
\hline - Pendidikan Rendah & 30 & 60,0 & 44 & 44,0 & \multirow[t]{2}{*}{0,094} & 1,909 \\
\hline - Pendidikan Tinggi & 20 & 40,0 & 56 & 56,0 & & $(0,958-3,806)$ \\
\hline \multicolumn{7}{|l|}{ Pekerjaan } \\
\hline - Tidak Bekerja & 27 & 54,0 & 59 & 59,0 & \multirow[t]{2}{*}{0,683} & 0,816 \\
\hline - Bekerja & 23 & 46,0 & 41 & 41,0 & & $(0,412-1,617)$ \\
\hline \multicolumn{7}{|l|}{ Kebiasaan Merokok } \\
\hline - Merokok & 20 & 40,0 & 29 & 29,0 & \multirow[t]{2}{*}{0,242} & 1,632 \\
\hline - Tidak Merokok & 30 & 60,0 & 71 & 71,0 & & $(0,801-3,326)$ \\
\hline \multicolumn{7}{|l|}{ Aktifitas Fisik } \\
\hline - Tidak Rutin & 49 & 98,0 & 96 & 96,0 & \multirow[t]{2}{*}{0,872} & 2,042 \\
\hline - Rutin & 1 & 2,0 & 4 & 4,0 & & $(0,222-18,764)$ \\
\hline \multicolumn{7}{|l|}{ Obesitas } \\
\hline - Obesitas & 15 & 30,0 & 21 & 21,0 & \multirow[t]{2}{*}{0,311} & 1,612 \\
\hline - Tidak Obesitas & 35 & 70,0 & 79 & 79,0 & & $(0,744-3,492)$ \\
\hline
\end{tabular}


Jurnal Akademika Baiturrahim Jambi, Vol. 9, No. 2 September 2020

Doi: $10.36565 /$ jab.v9i2.234

p-ISSN :2302-8416

e-ISSN: 2654-2552

\begin{tabular}{|c|c|c|c|c|c|c|}
\hline $\begin{array}{l}-\geq 200 \mathrm{~mm} / \mathrm{dl} \\
-\quad<200 \mathrm{~mm} / \mathrm{dl} \\
\end{array}$ & $\begin{array}{l}11 \\
39 \\
\end{array}$ & $\begin{array}{l}22,0 \\
78,0\end{array}$ & $\begin{array}{l}27 \\
73\end{array}$ & $\begin{array}{l}27,0 \\
73,0\end{array}$ & 0,642 & $\begin{array}{c}0,763 \\
(0,342-1,700) \\
\end{array}$ \\
\hline $\begin{array}{l}\text { GDP } \\
-\quad \geq 126 \mathrm{~mm} / \mathrm{dl} \\
-\quad<126 \mathrm{~mm} / \mathrm{dl}\end{array}$ & $\begin{array}{l}10 \\
40\end{array}$ & $\begin{array}{l}20,0 \\
80,0\end{array}$ & $\begin{array}{l}26 \\
74\end{array}$ & $\begin{array}{l}26,0 \\
74,0\end{array}$ & 0,543 & $\begin{array}{c}0,712 \\
(0,312-1,623)\end{array}$ \\
\hline $\begin{array}{l}\text { Kolesterol Darah Total } \\
-\quad \geq 200 \mathrm{~mm} / \mathrm{dl} \\
-\quad<200 \mathrm{~mm} / \mathrm{dl}\end{array}$ & $\begin{array}{l}20 \\
30 \\
\end{array}$ & $\begin{array}{l}40,0 \\
60,0\end{array}$ & $\begin{array}{l}16 \\
84 \\
\end{array}$ & $\begin{array}{l}16,0 \\
84,0\end{array}$ & 0,002 & $\begin{array}{c}3,500 \\
(1,607-7,623) \\
\end{array}$ \\
\hline $\begin{array}{l}\text { Trigliserida } \\
-\geq 150 \mathrm{~mm} / \mathrm{dl} \\
-\quad<150 \mathrm{~mm} / \mathrm{dl} \\
\end{array}$ & $\begin{array}{l}15 \\
35 \\
\end{array}$ & $\begin{array}{l}30,0 \\
70,0\end{array}$ & $\begin{array}{l}19 \\
81 \\
\end{array}$ & $\begin{array}{l}19,0 \\
81,0\end{array}$ & 0,190 & $\begin{array}{c}1,827 \\
(0,834-4,004)\end{array}$ \\
\hline $\begin{array}{l}\text { Riwayat Hipertensi } \\
\text { - Ada } \\
\text { - Tidak Ada } \\
\end{array}$ & $\begin{array}{l}44 \\
6 \\
\end{array}$ & $\begin{array}{l}88,0 \\
12,0\end{array}$ & $\begin{array}{l}55 \\
45 \\
\end{array}$ & $\begin{array}{l}55,0 \\
45,0\end{array}$ & 0,001 & $\begin{array}{c}6,000 \\
(2,345-15,353)\end{array}$ \\
\hline $\begin{array}{l}\text { Tekanan Darah Sistolik } \\
-\geq 140 \mathrm{mmHg} \\
-\quad<140 \mathrm{mmHg}\end{array}$ & $\begin{array}{l}37 \\
13 \\
\end{array}$ & $\begin{array}{l}74,0 \\
26,0\end{array}$ & $\begin{array}{l}45 \\
55\end{array}$ & $\begin{array}{l}45,0 \\
55,0\end{array}$ & 0,001 & $\begin{array}{c}3,479 \\
(1,652-7,325) \\
(\end{array}$ \\
\hline $\begin{array}{l}\text { Tekanan Darah Diastoli } \\
-\geq 90 \mathrm{mmHg} \\
-\quad<90 \mathrm{mmHg}\end{array}$ & $\begin{array}{l}24 \\
26 \\
\end{array}$ & $\begin{array}{l}48,0 \\
52,0\end{array}$ & $\begin{array}{l}25 \\
75 \\
\end{array}$ & $\begin{array}{l}25,0 \\
75,0\end{array}$ & 0,008 & $\begin{array}{c}2,769 \\
(1,353-5,667) \\
\end{array}$ \\
\hline $\begin{array}{l}\text { Pemeriksaan Jantung } \\
\text { - Ada Kelainan } \\
\text { - Tidak Ada Kelainan }\end{array}$ & $\begin{array}{l}34 \\
16\end{array}$ & $\begin{array}{l}68,0 \\
32,0\end{array}$ & $\begin{array}{l}43 \\
57\end{array}$ & $\begin{array}{l}43,0 \\
57,0\end{array}$ & 0,007 & $\begin{array}{c}2,817 \\
(1,379-5,752)\end{array}$ \\
\hline
\end{tabular}

\section{Analisis Multivariat}

Berdasarkan hasil analisis dengan responden dengan kadar kolesterol multivariat dengan uji regresi binary total $<200 \mathrm{mg} / \mathrm{dl}$. Faktor risiko selanjutnya logistic didapatkan hasil bahwa faktor adalah obesitas dengan $\operatorname{Exp}(\mathrm{B})$ sebesar risiko paling dominan yang mempengaruhi 2,217 (p-value 0,080; 95\% CI 0,910-5,401). terjadinya stroke non hemoragik adalah Responden obesitas memiliki kecendrungan riwayat hipertensi dengan $\operatorname{Exp}(\mathrm{B})$ sebesar 6,476 (p-value 0,$000 ; 95 \%$ CI 2,33817,935). Apabila memiliki riwayat hipertensi maka akan memiliki kecendrungan mengalami stroke non hemoargik 6,476 kali dibandingkan dengan yang tidak memiliki riwayat hipertensi. Faktor risiko setelah riwayat hipertensi adalah variabel kadar kolesterol total dengan $\operatorname{Exp}(\mathrm{B})$ sebesar 6,139 (p-value 0,000; 95\% CI 2,334-16,148). Apabila kadar kolesterol darah $\geq 200 \mathrm{mg} / \mathrm{dl}$, memiliki kecendrungan mengalami stroke non hemoragik 6,139 kali dibandingkan mengalami stroke non hemoragik 2,217 kali dibandingkan dengan yang tidak obesitas. Variabel selanjutnya adalah jenis kelamin dengan $\operatorname{Exp}(\mathrm{B})$ sebesar 0,379 (p-value 0,022; 95\% CI 0,165-0,871). Dan variabel terakhir adalah pandidikan dengan $\operatorname{Exp}(\mathrm{B})$ sebesar 0,311 (p-value 0,009; 95\% CI 0,129-0,747) (tabel 2).

Setelah itu ke lima variabel tersebut dimasukkan ke dalam persamaan regresi logistik didapatkan hasil bahwa, jika ke lima variabel tersebut ada pada responden maka risiko seorang mengalami Stroke non hemoragik 
Tabel 2. Model Akhir Regresi Logistik

\begin{tabular}{lccccc}
\hline \multicolumn{1}{c}{ Variabel Independen } & B & Wald & Sig & Exp.B & 95\% C.I \\
\hline Riwayat Hipertensi & 1,868 & 12,920 & 0,000 & 6,476 & $2,338-17,935$ \\
Kadar Kolesterol Total & 1,815 & 13,523 & 0,000 & 6,139 & $2,334-16,148$ \\
Obesitas & 0,796 & 3,070 & 0,080 & 2,217 & $0,910-5,401$ \\
Jenis Kelamin & $-0,970$ & 5,228 & 0,022 & 0,379 & $0,165-0,871$ \\
Pendidikan & $-1,169$ & 6,818 & 0,009 & 0,311 & $0,129-0,747$ \\
Constant & $-0,841$ & & & & \\
\hline
\end{tabular}

\section{Pembahasan}

Hasil analisis multivariat riwayat hipertensi merupakan faktor yang paling dominan penyebab dari Stroke non hemoragik dengan nilai $\mathrm{p}=0,000$, $\operatorname{Exp}(B)=6,476$; 95\% CI: 2,338-17,935.

Hal ini juga didukung dengan analisis bivariat bahwa tekanan darah sistolik $\geq 140 \mathrm{~mm} / \mathrm{Hg}$ dan tekanan darah diastolik $\geq 90 \mathrm{~mm} / \mathrm{Hg}$, memberikan pengaruh yang bermakna terhadap terjadinya Stroke non hemoragik dengan nilai $p$-value $<0,05$. Dengan masing-masing risiko hampir 3 kali dibandingkan dengan yang memiliki tekanan darah sistolik dan diastolik normal. Sehingga dapat dikatakan bahwa tingginya tekan darah sistolik dan diastolik dapat meningkatkan risiko terjadinya Stroke non hemoragik.

Hipertensi sebagai risiko yang paling umum menyebabkan Stroke. Dari 50 kasus, didapatkan 39 Kasus (78\%) menderita hipertensi, dengan nilai pvalue $=0,000$ dan Odds Rasio 4,16. Faktor risiko Stroke non hemoragik di 22 negara, membuktikan bahwa dari sepuluh faktor risiko yang diteliti hipertensi menjadi penyebab paling kuat yang mempengaruhi terjadinya Stroke non hemoragik (Donel 2010).

Sejalan dengan penelitian stroke pada usia muda, bahwa ada hubungan yang bermakna antara riwayat hipertensi dengan terjadinya Stroke non hemoragi, responden yang memiliki riwayat hipertensi berisiko 4.33 kali terkena stroke dibandingkan yang tidak memiliki riwayat hipertensi. Pada hasil analisis multivariat, riwayat hipertensi merupakan faktor risiko paling dominan terhadap terjadinya stroke non hemoragik dengan nilai p-value 0,001 $\operatorname{Exp(B):~5,76~95\% CI:~2,08-15,94~(~Sitorus,~}$ 2008).

Faktor risiko setelah riwayat hipertensi adalah Kadar kolesterol darah total merupakan faktor risiko paling dominan penyebab terjadinya Stroke Non Hemoragik. Adanya hubungan antara Stroke non hemoragik dengan kadar kolesterol total sesuai dengan penelitian sebelumnya bahwa sindrom metabolik responden yang tidak normal dapat menjadi pencetus serangan stroke. Sindrom metabolik yang merupakan faktor risiko stroke meliputi tekanan darah tinggi, gula darah meningkat, kegemukan dan dislipidemia (Riyadina,2010).

Hasil analisis multivariat dalam penelitian ini variabel pendidikan menjadi salah satu faktor risiko yang dominan menyebabkan stroke non hemoragik. Dengan nilai $\mathrm{p}$-value $=0,009 ; \operatorname{Exp}(\mathrm{B})$ : 0,311; 95\%CI: 0,129-0,747.

Sejalan dengan penelitian sebelumnya bahwa pendidikan tidak memiliki hubungan yang bermakna dengan Stroke dengan nilai $p$-value $=0,830$ pada rasponden dengan latar belakang pendidikan D3 maupun perguruan tinggi dan 0,60 pada responden dengan latar belakang pendidikan SMP-SMA ( Riyadina, 2013). Penelitian tentang pengetahuan faktor risiko stroke yang dilakukan pada 240 pasien, di pelayanan 
primer yang sebelumnya pernah mengalami stroke. Disebutkan bahwa pengetahuan tentang hipertensi, hiperlipidemia dan merokok sebagai faktor risiko yang dapat dijawab dengan baik oleh responden sebesar 90\% ( Sloma,2010).

hasil analisis multivariat secara bersama jenis kelamin merupakan salah satu variabel risiko yang tidak dapat dirubah yang mempengaruhi terjadinya stroke non hemoragik dengan nilai $\mathrm{p}=0,022, \operatorname{Exp}(\mathrm{B}): 0,379 ; 95 \%$ CI: 0,1650,871 .

Sejalan dengan penelitian pada responden yang mengalami menarce pada usia dini memiliki risiko penurunan yang signifikan sebesar 0.3 kali untuk mengalami Stroke iskemic (Hsieh, 2010).

Data di indonesia berdasarkan karakteristik jenis kelamin persentase penderita Stroke pada laki-laki $(7,1 \%$ lebih banyak $0,3 \%$ dari pada perempuan yaitu $(6,8 \%$, hal ini menunjukan penelitian ini sejalan dengan data tersebut $^{11}$. Selain itu insidensi Stroke pada perempuan lebih rendah dibandingkan laki-laki akibat adanya hormon estrogen yang berfungsi sebagai proteksi pada proses aterosklerosis ${ }^{14}$. Hal ini juga dapat dilihat dari distribusi Stroke non hemoragik menurut usia dalam penelitian ini, bahwa angka kejadian pada kelompok kasus diusia < 45 tahun lebih sedikit dibandingkan dengan usia $\geq 45$ tahun, hal ini dikaitkan dengan terjadinya penurunan hormon estrogen pada perempuan menopouse usia $>50$ tahun.

Proporsi kejadian Stroke non hemoragik pada responden obesitas dalam penelitian ini sebesar $30 \%$, dengan risiko terjadinya Stroke non hemoragik adalah 1,612 kali dibandingkan dengan yang tidak obesitas. Sedangkan dari hasil uji statistik didapatkan bahwa tidak ada hubungan yang bermakna antara obesitas dengan terjadinya Stroke non hemoragik dengan nilai $p=0,224$. Hasil analisis multivariat variabel obesitas merupakan salah satu faktor dominan yang berpengaruh terhadap terjadinya stroke non hemoragik.

Hasil ini sejalan dengan penelitian sebelumnya, dengan nilai $\mathrm{p}=0,307$ dan OR 0,566 (95\%CI: 0,232-1,383), Obesitas berhubungan dengan tingginya tekanan darah dan kadar gula darah, jantung bekerja lebih keras untuk memompa darah keseluruh tubuh, sehingga dapat meningkatkan tekanan darah. Oleh karena itu obesitas berkontribusi juga terhadap terjadinya stroke.

Hubungan langsung obesitas dengan stroke memang belum jelas. Namun obesitas biasanya berhubungan dengan pola makan, DM tipe 2, peningkatan kadar kolesterol dan peningkatan tekanan darah yang memicu terjadinya proses aterosklerosis.

\section{SIMPULAN}

Terdapat 5 variabel faktor risiko yang berpengaruh terhadap Stroke Non Hemoragik. Jika ke 5 variabel faktor risiko ini berinteraksi maka risiko seorang mengalami Stroke non hemoragik adalah $81.6 \%$.

Perlu dilakukan pencegahan dengan menjaga pola hidup sehat dan mengendalikan faktor risiko yang mempengaruhi terjadinya Stroke non hemoragik.

\section{DAFTAR PUSTAKA}

Donnel, M., Xavier, D., dan Liu, L. (2010). Risk Factor for ischemic and intracerebral hemorrhagic stroke in 22 countries. The Interstroke Study, 376:112-123.

Elim, C., Tubagus, V., \& Ali, R. H. (2016, juli). Hasil pemeriksaan CT scan pada penderita stroke non hemoragik. jurnal e-clinic, 4, 2. 
Ellis, C. (2010). Stroke in young adults. Disabil Health J, 222-224.

Hsieh, Y.-C. (2010). Early Menarche And Ischemic Stroke Risk. International Journal of gerontology: Vol:4,no 1

Kanyal, N. (2015). The Science of Ischemic Stroke: Pathophysiology \& Pharmacological Treatment. International Journal of Pharma Research \& Review, 4(10):65-84.

Kariasa, I. M. (2009). Persepsi pasien paska serangan stroke terhadap kualitas hidupnya dalam perspektif asuhan keperawatan. Jakarta: FIK UI.

Price, S., \& Wilson, L. (2005). Patofisiologi Konsep Klinis Prosesproses penyakit edisi I. Jakarta: EGC.

Riset Kesehatan Dasar (Riskesdas) 2013. Pedoman Pewawancara Petugas Pengumpul Data. Jakarta: Badan Litbangkes, Depkes RI, 2013

Riyadina, W., \& Rahajeng, E. (2013). Determinan Penyakit Stroke. Kesehatan Masyarakat Nasional: Vol 7;No.7.

Shah, S. M., Shah, S. M., Khan, S., Rehman, S. U., Khan, Z. A., \& Zubair. (2013). Addressing the impact of stroke risk faktor in a case control study in tertiary care hospitals. Biomed central, 6:268.

Sitorus, Rico Januar (2008) Faktor-Faktor Risiko Yang Mempengaruhi Kejadian Stroke Pada Usia Muda Kurang Dari 40 Tahun (Studi Kasus Di Rumah Sakit Di Kota Semarang). Jurnal Epidemiologi . (Unpublished)

Sloma, A., Backlund, L., Strender, L.-E., \& Skaner, Y. (2010). Knowledge of stroke risk factor among primary care patiens with previous stroke or TIA. BMC Family Practice: vol 11 no 47.

Smajlovic, D. (2015, November). Strokes in young adults: epidemiology.
Vascular Health and Risk Management, 157-164.

Wayunah. (2016). Analisis Faktor Yang Berhubungan Dengan Kejadian Stroke Di Rsud Indramayu. Jurnal Pendidikan Keperawatan Indonesia, 65-76.

Yuniardi, Y. (2010). Intervensi pada Stroke Non-Hemoragik. Jurnal Kardiologi Indonesia, 31:153-5. 